\title{
THE SWEDISH ASSOCIATION OF WASTE MANAGEMENT PERSPECTIVE ON LEACHATE TREATMENT
}

\author{
Thomas Rihm \\ The Swedish Association of Waste Management
}

Sweden

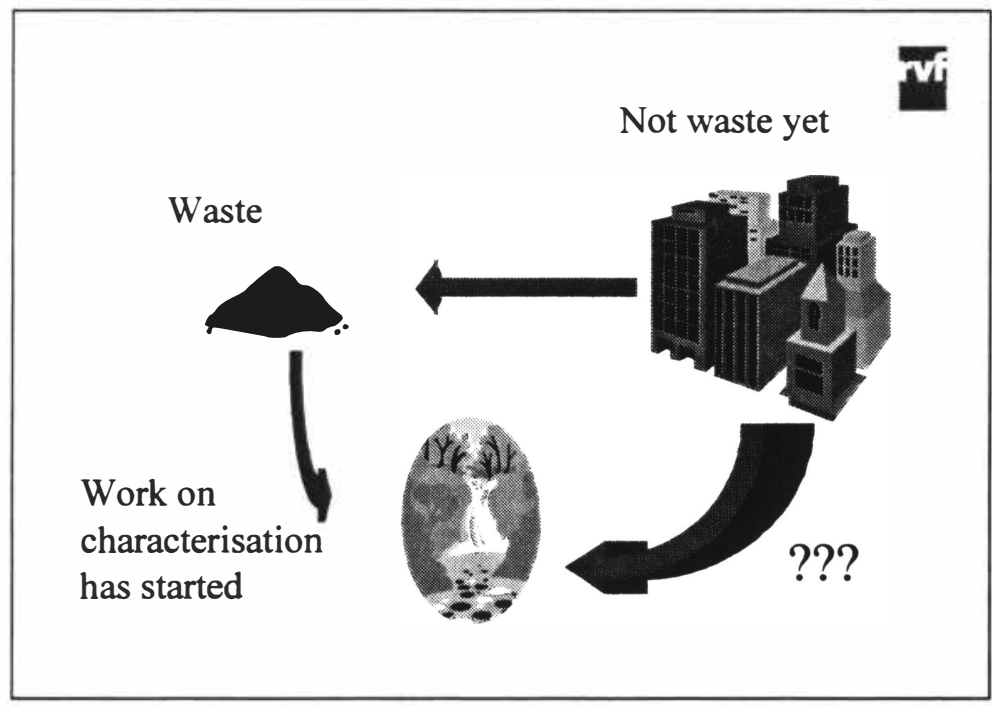

The contents of a landfill is ruffly the same as material in a town or city. If you were to put a city into a large shredder and then pile it in a heap you would end up with something very much similar to a landfill. Only about $2 \%$ of the material in our society has already become waste. The remaining $98 \%$ will become waste sooner or later. Yet ordinary people are very concerned about leachate from landfills. They are less concerned about what pollutants may arise as a consequence of their daily living. The daily living will result in a "leachate" (storm water runoff, sewage water etc.) Although the concentrations in this "leachate" may be very low, the flux is very high and the amount of pollutants may be considerable.

Although work on characterisation of leachate from landfills has started in order to get a better understanding of what pollutants are the most important to treat, it is important to understand that there are many thousands of substances in the leachate and it is only possible to analyse a small fraction of them. There is however one thing we know. If we use a substance in the society we will have it in our landfills, and we will have it in the leachate. It is only a matter of concentration. Thus true leachate treatment starts with measures to avoid the production and use of harmful substances and products. 


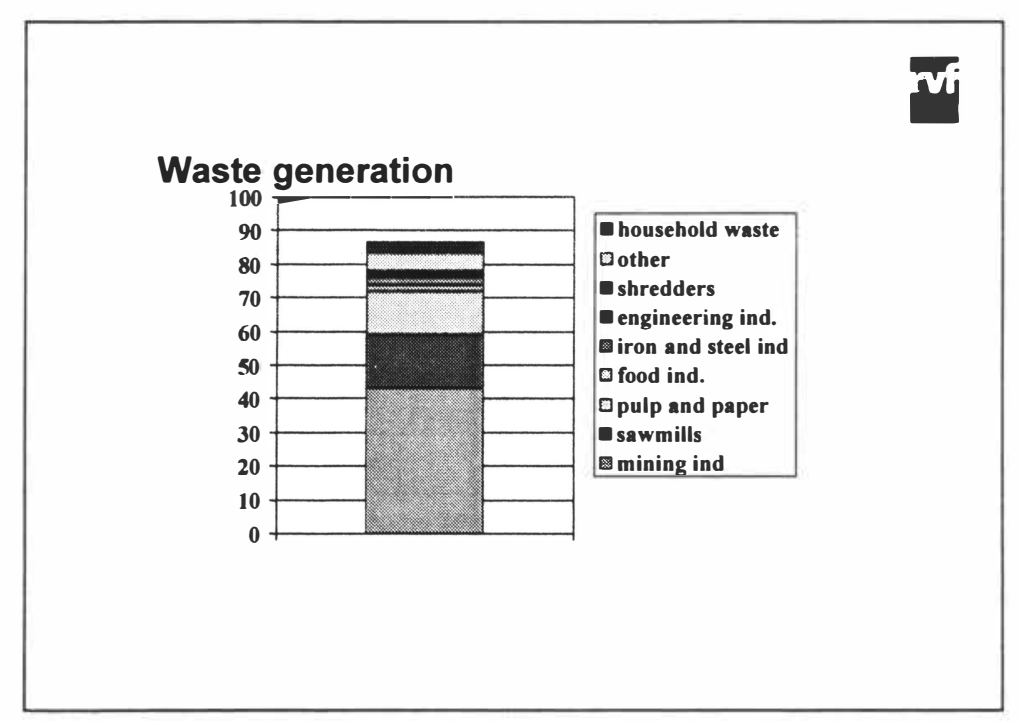

The waste generation in Sweden amounts to approximately 90 million tons. The statistics on industrial waste is pore so the figures are uncertain. The household waste amounts to only 3.8 Milton tons. Most of the waste comes from the mining industry, sawmills and paper industry. The special problems connected to these kinds of material is not discussed in this paper.

Although the municipal waste is a small part of the generated waste, it is the part that ordinary people think of when they think of waste and where demand for leachate treatment is strongest.

In Sweden approximately on third of the household waste is recycled, one third incinerated and one third landfilled. Landfilling of household waste has declined with about $20 \%$ the during last five years. This is due to a greater awareness among people about the environmental problems and people are prepared to cooperate with companies and local authorities to recycle as mush waste as possible. New incineration plants and enhancement of old ones also contributes less landfilling.

Although the degree of recycling is among the better in European countries there is still much work to be done. 


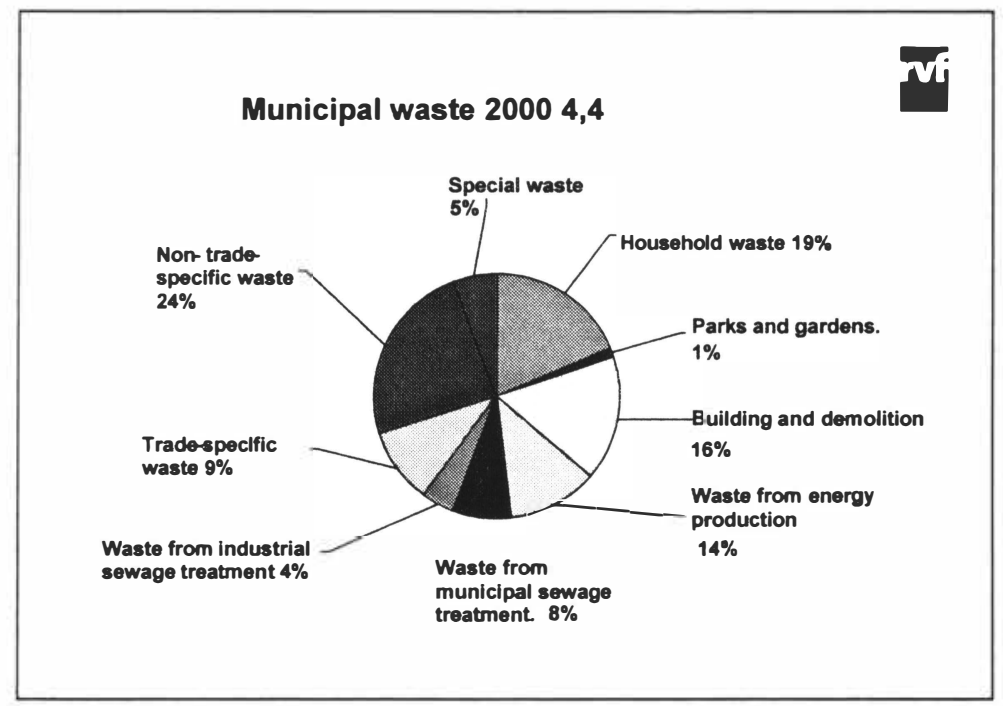

There are about 250 landfills for municipal waste in Sweden. The picture above shows what kind of wastes are landfilled. In fact, household waste only amounts to about $20 \%$ of the total amount landfilled. In addition to household waste and building and demolition waste, ashes, slaggs, sludges and some industrial wastes are also landfilled. The total amount of waste landfilled on these landfills amounts to 4.4 million tons.

Some special wastes are also landfilled. The main fractions are asbestous waste and contaminated soils. Contaminated soils containing hydrocarbons are often composted to reduce the contents of pollutants before landfilling.

The amount of waste landfilled will be lowered substantially in the future. From the beginning of 2002, combustible waste have to be sorted out and is not allowed to be landfilled. From 2005 organic waste is not allowed to be landfilled. This will alter the nature of the waste and the conditions within the landfills. It will most likely result in a change of the leachate quality and this must be taken into account when designing constructing leachate treatment plants. 


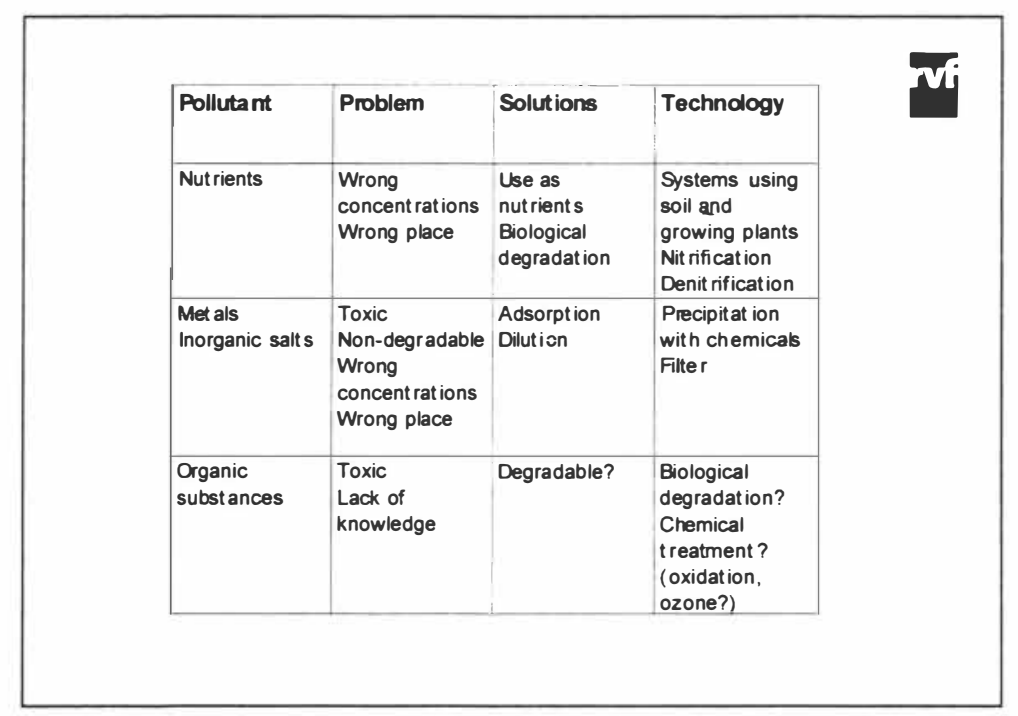

I can identify three different kinds of problems connected to the pollutants in the leachate from landfills.

The first one is the nutrients, especially nitrogen. The problem is that they occur in the wrong place and at the wrong concentrations. If we could use them in the appropriate concentrations in fertilisers we could solve the problem. There are also fairly well known technology with which the nutrients can be treated (nitrification and denitrification). There is still a need to find practical methods, using natural biological systems, to treat the leachate. There remains much to be done to design construct such systems and to find ways to achieve better estimations of their efficiency.

The other kind of problem is connected to metals and inorganic salts. Metals can not be destructed, we have to rely on that they are securely bound within the landfill or that we can precipitate them. Many salts such as sodium chloride not toxic to human beings but may present a problem to organisms living in fresh water regimes. Localisation of the landfill near the coast or near a recipient where the salt can be sufficiently diluted are key factors to avoid problems.

Concerning organic substances lack of knowledge is the main problem. 


\section{Leachate}

\begin{tabular}{|l|c|c|c|}
\hline & $\begin{array}{l}\text { Number } \\
\text { of plants }\end{array}$ & $\begin{array}{l}\text { Million } \\
\mathrm{m3}\end{array}$ & $\begin{array}{l}\text { Landfilled } \\
\text { waste } \\
\text { Million } \\
\text { tons }\end{array}$ \\
\hline Collect ion & 155 & 12,2 & 4,4 \\
\hline $\begin{array}{l}\text { Sewage } \\
\text { treat ment } \\
\text { plants } \\
\text { Local } \\
\text { treatment }\end{array}$ & 95 & 8,0 & 3,0 \\
\hline
\end{tabular}

The landfill sites in Sweden differ a lot in size. The 50 largest ones take about $75 \%$ of the waste. The 85 smallest ones take less than 3000 tons per year and the waste landfilled at those landfills does not amount to more than $2 \%$. The small sites are normally situated in the north of Sweden where the density of population is low.

There are about 150 landfill sites in Sweden with leachate collection systems. The a sites have without leachate collection are all small ones. All major sites have collection and in fact more than $90 \%$ of the waste is landfilled on sites with leacate collection. The leachate collected amounts to some 12 million cubic meters per year. About eight cubic meters are forwarded to sewage treatment plants.

Many sites have some kind of local treatment, but in many cases it may consist of simple aeration and the leachate is then sent for further treatment in a sewage treatment plant. In many cases only a small fraction the leachate is treated locally. 


\section{Techniques}

-83 Aerated ponds

-6 Precipitation with chemicals

-32 Recirculation to the landfill

-35 Irrigation, soil and vegetation

-46 Infiltration

-4 Sequenced batch reactors

-3 Filtration

-0 Reversed osmosis

A number of different techniques are used in Sweden for local treatment. The most common one is aeration. Other techniques used are precipitation using different chemicals, recirculation of the leachate to the landfill, irrigation of soil and vegetation, infiltration and filtration. A number of sequencing batch reactors have been built lately, and the results are reported to be very good.

Most treatment methods, even the more sophisticated ones, rely on natural processes. In the more complicated methods more efforts are made to enhance the conditions under which the natural processes take place and optimise the result. These efforts may be difficult to maintain in the long time perspective.

High-tech solutions such as reversed osmosis are rarely used in Sweden. The cost is high and they will produce a concentrate which is difficult to handle.

One of the main issues that has a great influence of which method to chose is whether the sludge from the sewage treatment plants is going to be used for agricultural purposes. The farmers organisation and the food producers in Sweden are reluctant to allow this. If the sludge is not intended to be used on the fields sewage treatment plant constructed for nitrogen removal can be used and local treatment can be focused on other pollutants. 

Whatever barriers and other
precautions we take, in the end it is always the natures ability to adsorb, degrade and dilute pollutants that we must relay on and thus the nature also sets the limit forlandfilling technology and for what substances can be accepted in a landfill

The importance of "natural" processes is emphasised in the Swedish Environmental protection agency's strategy for safe landfills where it is stated that in spite of all barriers and other precautions we take, in the end it is always the nature's ability to adsorb, degrade and dilute pollutants that we must rely on and thus the nature also sets the limit for landfilling technology and for what substances can be accepted in a landfill.

A total encapsulation of the waste will not be possible in a long time perspective. Time will inevitably cause failure to the encapsulating barriers. When this occurs we may even be in a worse situation than when the waste is put into the landfill.

As I have pointed out in the beginning it is therefore of great importance that we learm more about the substances and products $t$ we produce and that we carefully examine which ones we must avoid and which ones need destruction or special treatment before landfilling. 


\section{$\S 15$ Protection of soil and water}

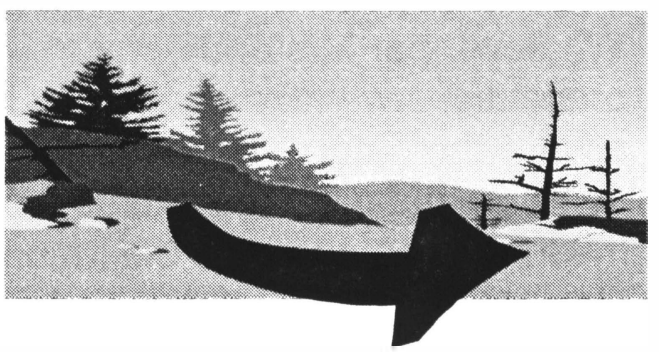

Class 1=200, Class 2 $=50$, Class $3=1$ year

The EC directive on landfilling prescribes that there must be a geological barrier and a liner and a leachate collection system under the waste. The liner and the collection system can be designed to last as long as the landfill is in operation. When the landfill is closed, the top cover will be the factor deciding how much leachat is being produced. The aim is to reduce the amount of leachat to a degree where the effect on the environment is acceptable.

The implementation of the EC-directive for landfilling in Swedish law is based on the fact that natural processes occur in the geological barrier. The thickness of prescribed barrier is recalculated into a minimum time it will take for the leachate to penetrate the barrier, thus giving the natural processes enough time.

The penetration time for landfills for hazardous waste is calculated to 200 years. For nonhazardous waste it is calculated to 50 years and for inert waste landfills to one year. 


\section{Work to be done}

-Which are the benefits and limitations with "natural" treatment systems and how can they be combined with other treatment methods?

-To what extent must the leachate be treated

-Risk assessments and comparisons with other sources of pollutants must be made in order to decide where invested money gives the most benefits

-More knowledge about substances and products is needed

-Better and cheaper analysis methods are needed

I think the cost effectiveness and the ability for "natural" systems to deal with some of the most common pollutants are widely recognised. There is still a lot work to be done in optimising the design and construction of full scale treatment plants.

Some of the most important questions to answer is whether specific substances need complementary treatment, and to what extent the leachat has to be treated. There is a risk that much money is invested in landfill leachate treatment and that other sources of pollution such as storm water runoff will be neglected. We have to carry out risk assessments and comparisons with these other sources to decide where invested money gives the most benefit. Due to the fact that leacate contains such vast amount of substances it is not possible to guarantee that no hazardous substances will remain in the treated leachate. Further research and developing of new and cheaper sampling and analyses methods is needed to improve the risk assessments and to make the comparisons with other sources of pollution. 